\title{
The Study and Practice on Teaching Reform of Signals and Systems Based on Comprehensive Talent Cultivation
}

\author{
Xiaojuan Wei \\ School of Electrical Engineering \\ Northwest University for Nationalities \\ Lanzhou, China \\ weixiaojuan925@126.com
}

\begin{abstract}
Signals and Systems" is the main technological base for the electric information program. The concept and method have already been widely applied to various aspects. With the development of information technology, existing course system and teaching contents are relatively lagging, so it is hard to meet demands of talent cultivation. There are lots of questions: repeated teaching contents with other courses, poor coordination, no organic whole, large mathematical analysis, weak linking theory with practice and disconnection among principles, methods and applications. As a result, it is urgent to reform the course and establish a kind of effective teaching model of the signal and system with the purpose of cultivating comprehensive talents. This is the important task of the current talent cultivation. In the paper, on the basis of the reflection on comprehensive talent cultivation, the author proposes specific measures on course teaching from teaching philosophy, teaching contents, teaching methods and teaching resources, etc.
\end{abstract}

Keywords-Study and Practice; reverse teaching design; diversified teaching method; Signals and Systems

\section{INTRODUCTION}

"Signals and Systems" is the basic theory of signal analysis and system analysis. It is an important basic course of undergraduate students in the electric information program. At present, lots of domestic colleges regard it as the subject in graduate record examination in some majors. The course is based on advanced mathematics, engineering mathematics and circuit principle, etc. It is the prerequisite course of subsequent digital signal processing, principle of communication and automatic control theory, etc., and plays a connecting link. Bad or good teaching quality relates to students' comprehension on important concepts, such as signal and system, etc., directly, as well as teaching quality of subsequent courses. As a result, effective improvement of teaching quality has the important significance on improving teaching quality of the electric information program and professional quality of students[1-2]. At the earlier stage of "the Signal and System", the school has applied the traditional teaching mode with a single form. Students generally think that the course has many formulas and strong theory. It is hard to understand it. Moreover, some courses many have repeated contents. As the course teacher, it is necessary to study and explore the teaching reform on the course.

\section{With THE GUIDANCE THOUGHTS OF "ACADEMIC ADMIRER AND PROJECT RETURN", INTRODUCE CORRESPONDING PROJECT CASES}

The course features include more mathematical formulas, abstract physical significance and large difficulties in utilization. Advanced multi-media technology is applied in the teaching process and project problems are introduced to the topic. This is an effective attempt to cultivate innovative and applied talents[3-5]. As a result, in the process of teaching basic concept and relevant theory, it is necessary to link theoretical knowledge with practical projects closely and combine teaching with scientific research originally, infuse project philosophy, and let students comprehend the important application of the theory intuitively, so as to guide scientific activities of students and improve project quality and practical ability of students. In classroom teaching, it is necessary to apply applied cases to motivate students' learning interests, reinforce their understanding on knowledge points and improve students' ability to analyze and solve problems comprehensively. With the theme of "the signal and system in projects", students may have the brand-new cognition. For example, imaging denoising and spectral analysis of the signal and system are a typical case in Fourier transform. The frequency shift property in Fourier transform, based on communication system of projects, the spectrum shifting process should be described: folding application in digital image processing and application of sampling theorem in signal sampling, etc. Such a teaching mode digs out the signal and system from life and projects, so that students' enthusiasm and learning interest will be greatly improved.

Beginning with the features of "the Signal and System", the course aims at improving teaching quality and cultivating comprehensive talents. It has the subjects of students and dominance of teachers, explores and practices the research study from theoretical teaching, experimental teaching, extracurricular studies and exchanges, and project practice, changes the traditional one-stop teaching mode, carries out the vertical and all-around teaching model, and enriches teaching means and teaching contents. It is necessary to link theoretical 
knowledge with practical projects, combine teaching and scientific research organically, improve students' learning interests, improve students' understanding on theoretical knowledge, and improve students' ability to solve systematic problems.

\section{REVERSE TEACHING DESIGN}

It plans to apply the "student-centered" teaching activity. In the teaching design, the "reverse teaching design" is applies. It means to design learning process facing to the ultimate goals with the center of learners. The reverse teaching design can be divided into three stages: Finally, complete content and organizational editing before formatting. Please take note of the following items when proofreading spelling and grammar:

Stage one: to set up learning achievements: the course is designed from the students' perspective. It aims at settling benefits gained by learning a course, such as ability or cognition, etc.

Stage two: to evaluate evidence: analysis design is implemented from the teachers' teaching, namely how to evaluate or test "learning achievements" and required contents of students.

Stage three: to learn design: Under the guidance of the above-mentioned ones, it is necessary to fabricate detailed steps in teaching and learning process.

It is mainly reflected in the following aspects: a) organize contents elaborately, propose teaching contents in the form of "questions" and "forms", let students form their own unique understanding on questions through independent study, and express their opinions through classroom discussion; b).Exercise class is organized by teachers; students give a speech; c) For application examples, research teaching is applied. Students concentrate on "questions", look for references, and obtain results through automatic study", as well as "express" their masterwork in classroom discussion; d) after students finish homework and in-class experiment, it is necessary to arrange students to discuss, so that students can display respective experimental achievements and experience.

By applying the reverse design thought and combining with external environment, course purpose and quality evaluation, it is necessary to design student-centered teaching with the purpose of changing the traditional teaching mode, cultivating learners' habits based on problem learning, and making learners become active and centered, and letting teachers become guiders and promoters of student learning. It can improve students' cognitive ability and independent learning capability, while teaching knowledge to students.

\section{Practice of the Diverse Teaching Methods}

The research teaching based on "problem driving" should be explored actively. In the teaching process, it is necessary to abide by the cognitive discipline and integrate with basic concepts, basic theories and basic methods through problem proposal, problem analysis, problem solution and problem extension, display knowledge charm, promote active thinking of students, cultivate autonomous learning ability and explorative spirit of students, and realize knowledge teaching, ability cultivation and quality education in teaching process. In teaching methods, it must combine classroom teaching, classroom discussion, simulation analysis experiment, and special discussion organically, teach students in accordance of their aptitude, develop subjective roles of students and leading roles of teachers in teaching activities, pay attention to enlightenment and interaction, concern the organic combination of principles, methods and applications, and link theory with practice to motivate students' learning interests.

In classroom teaching, it must apply the problem-driven teaching methods and guide students to learn course contents and master knowledge points by asking questions. Students also can propose questions, analyze and study together, and propose solutions. In spare time, students conduct special study and discussion on relevant problems through MATLAB simulation experiment, exchange and discuss in the class, expand their knowledge and improve the ability to solve problems.

In the experimental teaching, a teaching method of "three transforms" is proposed, namely to change experimental results orientation to experimental process orientation; change experimental answering to experimental guidance and enlightenment, and change single experimental mode to the diversified experimental mode. With the carriers of experimental contents, it must pay attention to phenomenon analysis in the experimental process, weaken experimental results, and look forward to make students "suffer from problems" in the experimental process. In this way, students can enhance their practice ability in the process of problem analysis and problem solving.

\section{INTEGRATION AND UPDATING OF TEACHING CONTENTS}

In content updating, it proposes an opinion that knowledge has no difference of being "useful" and "useless", but has the difference of being "useful" and "more useful". It must pay attention to valuing presentation of knowledge, try to improve students' cognitive ability and independent learning ability, while teaching knowledge to students, concentrate on project application, ensure completeness and rigorousness of theoretical contents, but won't limit to the tedious and boring theoretical derivation, teach relevant knowledge to students by aiming at students features, conform to students' cognition and learning principles.

The teaching tasks of "Signals and Systems" still use a typical method to study uncertain signal and give priority to linear time invariant system, stand out physical conception and project conception of time-domain analysis and changing domain analysis of signal and system[6]. The key contents include typical signal and system nature, response decomposition of linear system, convolution and its significance, nature and application of Fourier transform and Z transform, systematic function, frequency response characteristics, sampling theorem and filtering, especially for emphasizing mathematical concepts, physical concepts and project concepts of three transforms(Fourier transform, Laplace transform and $\mathrm{Z}$ transform), and stressing on signal frequency spectrum and system function concept. On the basis of 
ensuring analysis methods and problem-solving systematicness and completeness, it must reinforce analysis of discreet signal and lay a solid foundation on discrete-time signal analysis and digital system design. Due to the application of project software(MATLAB and SPICE, etc.), solution of differential equations and difference equation, solution of circuit equation and inverse transformation are key points.

\section{COnstruction And PERfection of TeAching Resources}

It is necessary to attempt and study network assisted instruction, such as upload teaching contents, online teacherstudent discussion or even online homework etc. In contents, it must embody the organic combination of classics and modern, theory and technology, analysis and simulation. In systematic structure, it must value presentation of knowledge, embody the process of exploring, compacting and applying knowledge, and stand out mathematical concepts, physical concepts and project concepts in theories and methods. With study, students not only can acquire knowledge, but also can improve cognitive ability and cultivate explorative spirit.

Based on the Blackboard teaching platform, it contains teaching resources of signal and system, including courseware, knowledge points, trouble shooting, typical example question tank, exercise tank, construction of relevant teaching database, and create the online learning environment for students and teachers to cooperate, exchange, discuss and study. Teaching websites abide by individual learning theories, begin with students' features, have the targets of developing and cultivating comprehensive talents, and establish the online teaching environment of students' self-management and independent study. In teaching websites, they not only have course teaching contents facing to teaching demands, but also have various learning resources to expand students' knowledge. Students can select required knowledge contents according to their ability, level, habits and choices, etc.

\section{CONCLUSIONS}

"Signals and Systems" have some features, including more contents, strong theory and more mathematical formulas". In teaching links, it must link theory with practice, value practical teaching and improve students' comprehensive applied ability, and try to construct the course into the high-level and highquality course with scientific and reasonable teaching contents, abundant and innovative teaching contents, characteristic highlevel textbooks and abundant auxiliary teaching materials, diversified teaching methods and modern educational technology, etc.

\section{ACKNOWLEDGMENT}

This work is supported by Fundamental Research Funds for the Central Universities of Northwest University for Nationalities of China (Grant 31920140061) , and by the Teaching Reform Project of Northwest University for Nationalities of China.

\section{REFERENCES}

[1] LUO YI, "Research and Practice of Integration of Two Courses "Signals and Systems" and "Digital Signal Processing"," Journal of Jishou University ( Natural Science Edition), vol. 32 No.1, pp. 117-119, Jan. 2011.

[2] LIU Changzheng, ZHOU Libo, ZHANG Renwei, ZHANG Hongrui, "Reform of Signals and Systems Teaching for Applied Talents Cultivation," Computer Education, No.16, pp. 29-32, Aug. 2011.

[3] Manolaki sD G, Ingle V K , Kogon S M .St atistical and Adaptive Signal Processing[ M] . Beijing: Tsinghua University Press, 2003 .1-30

[4] Sanjit K Mitra. Digital Signal Processing-A Computer-Based Method [ M] .The Second Edition . Beijing: Tsinghua University Press , $2001.12-40$.

[5] Oppenheim A V, Schafer R W, Buck J R. Discrete-Time Signal Processing(The Second Edition)[ $\mathrm{M}]$. Beijing: Tsinghua University Press ,2005.693-754

[6] Roberto Cristi. Modern Digital Signal Processing[M] . Beijing: Machinery Industry Press, 2005.1-25. 